This is an electronic reprint of the original article. This reprint may differ from the original in pagination and typographic detail.

Author(s): Ngwayuh, Elvis Nshom; Croucher, Stephen

Title: $\quad$ Perceived threat and prejudice towards immigrants in Finland : A study among early, middle, and late Finnish adolescents

Year: $\quad 2017$

Version:

Please cite the original version:

Ngwayuh, E. N., \& Croucher, S. (2017). Perceived threat and prejudice towards immigrants in Finland : A study among early, middle, and late Finnish adolescents. Journal of International and Intercultural Communication, 10(4), 309-323. https://doi.org/10.1080/17513057.2017.1312489

All material supplied via JYX is protected by copyright and other intellectual property rights, and duplication or sale of all or part of any of the repository collections is not permitted, except that material may be duplicated by you for your research use or educational purposes in electronic or print form. You must obtain permission for any other use. Electronic or print copies may not be offered, whether for sale or otherwise to anyone who is not an authorised user. 
PERCEIVED THREAT AND PREJUDICE TOWARDS IMMIGRANTS IN FINLAND: A STUDY AMONG EARLY, MIDDLE AND

LATE FINNISH ADOLESCENTS

by

Nshom, E. \& Croucher, S. M. (accepted) 
Nshom, E. \& Croucher, S. M. (accepted). Perceived threat and prejudice towards immigrants in Finland: A study among early, middle and late Finnish adolescents. Journal International and Intercultural Communication

\title{
Perceived threat and prejudice towards immigrants in Finland: A study among early, middle and late Finnish adolescents
}

By

Elvis Nshom and Stephen Croucher

Department of language and communication studies

University of Jyväskylä, Jyväskylä, Finland

\begin{abstract}
Using integrated threat theory (ITT), this study examined how perceived threat, or fear of immigrants, manifests among early, middle, and late Finnish adolescents and the relationship between perceived threat and prejudice among Early, Middle, and Late adolescents. The total sample consisted of 795 Finnish adolescents between 11 and 19 years of age. Realistic and symbolic threats were the most perceived threats and were more prevalent among Late Adolescents. There was a positive relationship between prejudice and realistic threat and between prejudice and symbolic threat, but a negative relationship between prejudice and negative stereotyping and this relationship remained relatively stable from early to late adolescence. Implications are also discussed.
\end{abstract}

Key words: Prejudice, adolescents, integrated threat, Finland, immigrant. 


\section{Background}

Despite the continuous rise in immigration and an attempt to manage immigration in Europe, anti- immigrant threat and prejudice remains a major concern at the individual and societal levels, and more often than not surfaces as a key political, economic, and social issue. With a current immigrant population of over 200,000 (Statistics Finland, 2014), Finland has traditionally been viewed as a homogeneous society and highly excluded from the consequences of massive immigration (Kyntäjä, 1997). However, from 1990 to 2002 the number of immigrants tripled, but accounted for less than three percent of the total population (Ervasti, 2004). Research has shown anti-immigrant prejudice in Europe in general, and Finland in particular, is relatively widepread (Jaakola, 2000, 2009; Jasinskaja-Lahti \& Liebkind, 2001; Schneider, 2008; Tarvas \& Martikainen, 2012). According to Schneider (2008), one of the core explanatory factors for such widespread anti-immigrant attitudes is threat perception. Attitudes towards immigrants and immigration in Finland have become less positive especially amidst the outbreak of the current refugee crises in Europe. This has even led to anti-immigration demonstrations especially in the capital area (Helsinki) (Yle, 2015). Not long ago, Finland made headline news as anti-immigrant protesters threw rocks and fireworks at a bus transporting asylum seekers to a reception center in Lahti, Southern Finland (Reuter, 2015). Most Finns often worry about an increase in unemployment, the economic burden immigrants would pose to the Finnish government and the danger immigrants represent to the Finnish culture and society (Pitkänen \& Kouki, 2002; Yle, 2013). Research has shown believing people from other cultures are a threat to one's own culture and survival can lead to prejudice and discrimination towards people from other cultures such as immigrants (Croucher, Galy-Badenas, Routsalainen, 2014; Stephan, Diaz-Looving, \& Duran, 2000). In other studies, threats have been found to predict prejudice and to be positively 
related to prejudice and negative attitudes towards immigrants (Stephan \& Stephan, 1996, 1998).

According to Stephan and Stephan's $(1996,1998,2000)$ integrated threat theory (ITT), prejudice and negative attitudes towards immigrants and outgroups, can be related to four types of threats: realistic threat, symbolic threat, negative stereotype, and intergroup anxiety. Realistic threats are threats to the physical wellbeing, economic and political power of the in-group; symbolic threats are threats that arise because of cultural differences in values, morals and worldview of the out-group; negative stereotype are threats that arise because of negative stereotypes the in-group has about the outgroup, and intergroup anxiety refers to the anxiety the in-group experiences in the process of interaction with members of the out-group especially when both groups have had a history of antagonism (as in the case of Finland and Russia).

In Finland, few studies have empirically investigated threats posed by immigrants to the majority Finnish population (e.g., Croucher, Aalto, Hirvonen, \& Sommier, 2013; Nshom \& Croucher, 2014) and even though ITT (Stephen \& Stephan, 1996, 1998) has been widely used in other parts of the world to understand threats posed by immigrants and minority groups among different samples (e.g., Curseu, Stoop, \& Schalk, 2007; González et al., 2008; Ljujic, Vedder, \& Dekker, 2012; Scheibner \& Morrison, 2009; Stephan et al., 2000; Stephan, Ybarra, Martinez, Schwarzwald, \& Turk-Kaspa, 1998), these studies have not considered how differently early, middle, and late adolescents percieve immigrants as threatening. The goal of this study is to fill this research gap. This study is also an attempt to introduce an integrated threat perspective to the study of prejudice development from early to late adolescence and at the same time a contribution to research on ITT by showing its applicability in a developmental setting. In this study, we first examine the extent to which 
Finnish adolescents feel threatened by immigrants and subsequently how differently threat and prejudice manifests itself among Early, Middle, and Late Adolescents.

On the other hand, even though research has empirically found a relationship between percieved threat and prejudice (Stephan \& Stephan, 1993, 1996), scholarship has not investigated the stability of this relationship. Another dimension in this study is to understand the extent to which Finnish adolescent's prejudice towards immigrants is related to percieved threat and the extent to which this relationship remains stable from early to late adolescence. This is particularly important because studies on prejudice development (see Raabe \& Beelmann, 2011 for a review), have not considered threats while studies on threat and prejudice (see Riek et al., 2006 for a review) have not considered a developmental perspective.

Adolescence is a crucial developmental stage because these individuals represent the next generation of policy makers and it is also throughout these years that prejudice and attitude towards outgroups form and crystalize (Kiesner, Maass, Cadinu, \& Vallese, 2003). By describing their experiences of threat and prejudice towards immigrants, and clearly differentiating between Early, Middle, and Late adolescents, we gain important and vital information about specific target variables to focus on in an attempt to develop or enhance prejudice reduction strategies towards immigrants, which is a worthwhile social investment for the future (White, Wootton, Man, Diaz, Rasiah, Swift, \& Wilkinson, 2009).

\section{General research on Prejudice}

Human history has been plagued consistently with intergroup prejudice and conflict (Webstar, Saucier, \& Harris, 2010). Prejudice has been defined and studied differently (e.g., Allport, 1954; Buss, 1961; Carter \& Rice, 1997; Meertens \& Pittergrew, 1995, 1997; Oskamp, 1991, 2000; Rus \& Madrid, 1998); but according to Allport (1954) prejudice is a negative attitude towards someone who belongs to a group simply because he is a member of that 
group and is presumed to have the qualities ascribed to the group. He insists it is based on a faulty generalization. Personality threats, membership in a particular group, and cultural differences among others have traditionally been considered causes of prejudice (Allport, 1954; Pettigrew \& Meertens, 1995). However, concerning children and adolescents, attention has particularly been given to factors such as classification skills, group norm understanding (Abrams \& Rutland, 2008; Bergen, 2001; Raabe \& Beelmann, 2011), moral development (Killen, Margi, \& Sinno, 2006), motivational factors (Aboud, 1988; Tajfel \& Turner, 1979) such as ethnic awareness and identity development (Nesdale, 1999), social environmental factors such as intergroup contact (White et al., 2009), parents attitude (White \& Gleitzman, 2006) and friendship with out-groups (White et al., 2009).

There is extensive research on prejudice development in children (e.g., Aboud, 1988; Bigler \& Liben, 2006; Doyle \& Aboud, 1995; Nesdale, 1999), but very little is known about the development of prejudice in adolescence (Kiesner et al., 2003). Most prejudice development theories and research have focused on children from the ages of 4-12, looking at the role of social-cognitive developmental and motivational processes (Aboud, 1988; Tajfel \& Turner, 1979). Very little is known about the experience of threat and prejudice from ages 10 to 20 (White et al., 2009).

\section{Integrated threat theory (ITT) and prejudice}

Within the last two decades, Integrated Threat Theory (ITT) has been widely used to explain prejudice towards immigrants. Its basic contention is that perceived threat and negative belief about an outgroup tend to usually have the tendency to express itself in prejudicial actions or negative attitude (Stephan \& Stephan, 1993, 1996). This has been demonstrated in many studies (e.g., Curseu, Stoop, \& Schalk, 2007; González et al 2008; Scheibner \& Morrison, 2009; Stephan et al., 2000; Stephan, Ybarra, Martnez, Schwarzwald, \& Tur-Kaspa, 1998). Literature on ITT suggests prejudice can be caused by four types of threats. These 
are realistic threats, symbolic threats, intergroup anxiety, and negative stereotypes (Stephan et al., 1998, 1999; Stephan \& Stephan, 1996).

Realistic threat gained its theoretical basis from the realistic group conflict theory (Schweitzer et al., 2005). According to Stephan and Stephan, (1996), these are fears related to economic and political power, physical or material well-being of the ingroup or its members. According to González et al. (2008), this fear arises because of competition over scarce resources such as houses and jobs. The ingroup may feel their resources are being threatened by the outgroup or outsiders. The desire of the ingroup to protect their interest becomes the motivation responsible for prejudice, negative attitudes and discriminatory behavior towards the outgroup. This usually happens when social groups living together in a shared context compete for scarce resources and develop conflicting goals (Curseu et al., 2007). For example, immigrants living in Finland are often blamed for rising unemployment and economic difficulties (Finnish National Broadcasting Company, 2011; Jaakola, 2009).

Symbolic threats are threats due to perceive group differences in their world view, religion, culture, values, morals, attitudes and beliefs, just to name a few. Because of these perceived differences, ingroup members often have the tendency to dislike members of the outgroup and consequently prejudice them (Stephan et al., 2000). For example, Muslim immigrants in Europe and in Finland are usually perceived negatively because of differences in their religion and values (Jaakkola, 2009).

Intergroup anxiety refers to the anxiety that usually occurs when ingroup members are interacting with outgroup members. Outgroup members could feel this way because of the fear of being embarrassed, ridiculed or exploited by the other or if there exists some history of antagonism between the two groups (Nshom \& Croucher, 2014; Stephan et al., 2000). Studies have shown an increase in intergroup anxiety leads to an increase in the feeling of threat (Islam \& Hewstone, 1993). According to Croucher, Homsey, Brusch, Buyce, DeSilva, 
and Thompson (2013), intergroup anxiety is an individual level fear rather than a group level fear like the other fears. Since the focus of this study is on group level fears, intergroup anxiety is not included.

Negative stereotypes occur when ingroup members believe members of an outgroup are rude, selfish, flirtatious, aggressive, dishonest, or whatever negative attribute or stereotype one could think about, they will expect interactions with them to be negative and this could lead to negative attitudes towards the "other" (González et al., 2008). Negative stereotypes can produce fear that can affect the process of interaction between the majority and minority (Verkuyten, 1997). For example, Russian immigrants in Finland have historically and traditionally been perceived as the enemy due to a history of conflict and antagonism between Russia and Finland (Karamaa, 2004).

\section{Research hypotheses}

Previous research on prejudice in childhood and adolescence is to some extent marred with controversy and inconsistency with regards to age related changes associated with prejudice (Raabe \& Beelmann, 2011). However, research shows prejudice development has often been characterized by a nonlinear trend with an increase until the age of 7 , a decrease until the end of elementary school and another increase from early Adolescence (Raabe \& Beelmann, 2011). Some studies have also found a corresponding peak in prejudice from early adolescence (e.g., Black - Gutman \& Hickson, 1996; Kiesner et al. 2003; Rutland, 1999). However, from early Adolescence to late adolescence, prejudice is said to decrease (White et al., 2003). For example, Van Zalk and Kerr, (2014) in their study on developmental trajectories of prejudice and tolerance toward immigrants from early to late adolescence, found a strong normative decline in prejudice towards immigrants from early to late adolescence. Similarly, according to Hoover and Fishbein (1999): 
“there are three theoritical views that 'indirectly' leads to the prediction of a decrease in prejudice with increasing age from 10 to 20: (i) Fischer and Lamborn (1989) propose that because prejudice stems in part from simplistic social thinking that, as adolescents move towards more abstract levels, prejudice should decline; (ii) Katz and Ksansnak (1994) model predicted that gender role flexibility increases with age in adolescence due to an interaction between increasing cognitive flexibility and socialization influences, and this model when extended to prejudice predicts a decrease with age; and (iii) Kohlberg and Candee (1984) theorize that moral development generally increases from preadolescence to young adulthood because prejudice can involve action against target groups it can be seen as a proxy for moral action" (White et al., 2009, p. 525).

Since in this study we consider ITT (realistic threat, symbolic threat, and negative stereotypes) as a factor in our attempt to examine how differently early, middle and late Finnish adolescents perceive threat from and prejudice towards immigrants, the following descriptive research question and hypothesis is proposed:

RQ1: To what extent do Finnish adolescents perceive threat (symbolic threat, realistic threats and negative stereotypes) from immigrants?

H1: Threat and prejudice will be lower among late adolescents and higher among early adolescents.

In addition, even though perceived threat has been found to be positively related to prejudice (Riek et al., 2006; Stephan \& Stephan, 1993, 1996; Stephan et al., 1998; Stephan et al., 1999), the stability of this relationship has not been studied particularly adolescents. In this study, we first examine the extent to which Finnish adolescent's prejudice towards immigrants is related to perceived threat and second we attempt to show the extent to which that 
relationship remains stable from early to late adolescence. In order to do this, we propose the following hypothesis and research question:

H2: There will be a positive relationship between perceived threat and prejudice among Finnish adolescents.

$R Q 2:$ To what extent will the correlation between threat and prejudice differ between Early, Middle, and Late Finnish Adolescents?

\section{Method}

\section{Participants and Procedures}

Data were collected from three cities in Finland: Jyväskylä, Helsinki, and Joensuu. The participants were Finnish students from grades six to upper secondary school with an age range of 11 to 19 years of age. Data were collected through self-administered questionnaires and the primary researcher made sure it conformed to the established institutional ethical guidelines. The study was approved by the city council and principals of the schools. Out of 795 participants, 459 (57.7\%) were female while $336(42.3 \%)$ were male. Also, 157 (19.7\%) of the total sample were between 11 to 13 years old (early adolescents); 362 (45\%) were between 14-16 years of age (middle adolescents), and 276 (34.7\%) were between 17-19 years of age (late adolescents). Since the aim of this study is to understand the experience of threat and prejudice in adolescence, these age categories were created based on developmental periods in adolescence: early adolescents (11-13 years), middle adolescents (14-16 years), and late adolescents (17-19 years) (Raabe \& Beelmann, 2011; Valsiner \& Connolly, 2003). All participants were native born Finns. The researcher organized data collection trips to the schools after obtaining official authorization from the appropriate university and school authorities. Participation was voluntary and participants were not compensated for their participation. It took approximately 10 to 15 minutes to complete the questionnaire. ${ }^{1} \mathrm{~A}$ pretest 
was conducted in order to make sure all participants, especially the youngest ones, understood the questions clearly. Results indicated that questions were clearly understood even by the youngest participants.

\section{Measures}

The questionnaire included demographics measure, a measure of symbolic threat (González et al., 2008), a measure of realistic threat (González et al., 2008), a measure of negative stereotypes (González et al., 2008), and a measure of prejudice (Stephan \& Stephan 2002). The survey was originally prepared in English and then translated/back-translated into Finnish by native speakers of Finnish-English. Participants were asked throughout the survey to respond to questions about immigrants and not a particular immigrant group. This decision was made to ascertain how adolescents feel about the generic "immigrant" and not a specific immigrant group as the term is often understood by adolescents to mean those that look or speak differently from the majority irrespective of where they come from (Egharevba, 2011). See Table 1 for the means, standard deviations, correlations, alphas, and kappas for the study variables.

Realistic Threat: Realistic threat was assessed by asking participants to respond to three statements. These statements were: "Because of the presence of Immigrants, Finns have more difficulty finding a job", "Because of the presence of Immigrants; Finns have more difficulty finding a house," and "Because of the presence of Immigrants, unemployment in Finland is increasing". These scales were adapted from (González et al. 2008) and showed an alpha reliability of .80 . Response categories ranged from (1) strongly disagree to (5) strongly agree. Higher scores indicate more perceived threat. This current study showed an alpha reliability of .89 for realistic threat.

Symbolic Threat: In order to measure symbolic threats, three items from González et al. (2008) were used. These included "Finnish identity/culture is threatened because there are too many Immigrants today", "Finnish norms and values are threatened because of the pres- 
ence of Immigrants today," and "Immigrants are a threat to Finnish culture". Responses ranged from (1) strongly disagree to (5) strongly agree. Higher scores meant stronger feelings of threat. The alpha reliability for this scale was .89 in the original (Gonzalez et al., 2008) but this current study showed an alpha reliability of .85 for symbolic threat.

Stereotypes: Negative stereotype was assessed by asking participants to what extent 8 trait adjectives (violent, dishonest, unintelligent, friendly, arrogant, kind, greedy, and inferior) fully described immigrants. Friendly and kind were reversed scored. The alpha reliability for these traits in the original was .83 (Gonzalez et al., 2008) and in this current study was 85 . Responses ranged from (1) no, absolutely not, to (5) yes, certainly.

Prejudice: Participants were given six evaluative and emotional reactions and were asked to indicate to what extent these items reflected how they felt towards immigrants. This scale was adapted from Stephan and Stephan (2002). The items that made up the scale were as follows: "Acceptance, approval, admiration, antipathy, disdain, and disrespectful". Acceptance, approval and admiration were reverse scored and an alpha reliability coefficient of .71 was obtained for prejudice in this study. Responses ranged from (1) totally disagree to (5) absolutely agree. Higher scores indicated more feelings of prejudice towards immigrants. Insert Table 1 here

\section{Results}

Research question one asked the extent to which Finnish adolescents perceive threat (symbolic threat, realistic threats, and negative stereotypes) from immigrants. Table 1 details the means and standard deviations of the combined sample and the means and standard deviations of each sub-sample (early, mid, and late adolescents). $H 1$ proposed threat and prejudice would be lower among late adolescents and higher among early adolescents. To test $H 1$, a 3 (student) X 4 (prejudice, symbolic threat, realistic threat, and stereotypes) multiple analysis of variance (MANOVA) was conducted. The independent variable, student is categorical. 
The dependent variables are continuous. There was a significant effect of type of student on the independent variables, $\lambda=.96, F(8,1224)=3.50, p<.05$. Games-Howell post-hoc analysis showed significant differences between the different student groups and prejudice, symbolic threat, realistic threat, and stereotypes. See Table 2 for post hoc results. On prejudice, 17-19 year olds $(M=3.97, S D=.55)$ scored significantly higher than both 14-16 year olds $(M=3.81, S D=.76)$, and $11-13$ year olds $(M=3.77, S D=.70)$. On symbolic threat, $17-19$ year olds $(M=3.96, S D=1.20)$ scored significantly higher than $14-16$ year olds $(M=3.57$, $S D=1.30)$ and $11-13$ year olds $(M=3.71, S D=1.40)$. Similarly, on realistic threat, 17-19 year olds $(M=3.77, S D=1.10)$ scored significantly higher than $14-16$ year olds $(M=3.43$, $S D=1.20)$ and $11-13$ year olds $(M=3.47, S D=1.30)$. On negative stereotypes, 17-19 year olds $(M=1.93, S D=.54)$ scored significantly lower than $14-16$ year olds $(M=2.21, S D=$ $.78)$ and $11-13$ year olds $(M=2.17, S D=.81)$. Thus, counter to what was predicted, Late adolescents scored higher on prejudice, symbolic threat, and real threat than early adolescents. early adolescents did however score higher on stereotyping.

Insert Table 2 here

A one-tailed Pearson correlation was conducted to test $H 2$, which asserted that for Finnish adolescents there would be a positive correlation between threat and prejudice. The correlation results for the full sample are presented in Table 1. Based on the correlation analysis, the hypothesis is partially supported: prejudice is positively correlated with realistic threat $(r=.21, p<.01)$, and with symbolic threat $(r=.25, p<.01)$. However, prejudice is negatively correlated with stereotyping $(r=-.64, p<.001)$. This trend continued when the sample was divided into Early, Middle, and Late adolescents; see Table 1 for the full correlation results.

To answer RQ2, to what extent will the correlation between threat and prejudice differ between Early, Middle and Late Finnish Adolescents, a Fisher's z comparison of corre- 
lations was computed for each correlation (prejudice $\mathrm{X}$ threat). The results suggested the correlations between threat and prejudice did not significantly differ between the different age groups. See Table 3 for the full Fisher's z-results.

Insert Table 3 here

\section{Discussion}

This study set out to investigate to what extent Finnish adolescents perceive threat (realistic threat, symbolic threat, and negative stereotypes) from immigrants and how differently threat and prejudice manifest between Early, Mid, and Late adolescents. Results suggested Finnish adolescents in general do have a significant amount of prejudice towards immigrants. It was also suggested that Finnish adolescents are more likely to percieve immigrants as a realistic threat and a symbolic threat than to negatively stereotype them. This implies that the kind of fear Finnish adolescents have when it comes to immigration or immigrants is one related to economic issues. For realistic threats, the core issue is perceived competition over scarce resources, and the perception that these resources are threatened by outsiders (González et al., 2008). For example, immigrants living in Finland have often been blamed for rising unemployment and economic difficulties (Finnish National Broadcasting Company 2011; Jaakola, 2009). Morever, research has indicated attitudes towards immigrants in Finland became even sterner during the downturn of the economic crises (Jaakkola, 2000). On the other hand, the idea that Finnish adolescents percieve a significant level of symbolic threat suggests their fear is also related to differences in values, beliefs, worldview, norms or culture with immigrants. This is the case for example with Muslim immigrants in Finland who have often been viewed negatively because of negative media depictions (Croucher et al., 2013; Jaakkola 2009). This is a revelation that neccesitates interventions that can reduce these fears (realistic and symbolic threat) among adolescents as these fears have often been found in many samples and settings to lead to prejudicial actions 
against the outgroup (González et al., 2008; Khan \& Wiseman, 2007; Ljujic, 2011; Scheibner \& Morrison, 2009; Schweitzeret al., 2005; Stephan, et al., 1998, 2000; Stephan \& Stephan, 1996). These results therefore support the vast body of research that explore threats from the majority through the theoritical lens of ITT (Nshom \& Croucher, 2014; Stephan et al., 1998). Moreover, based on previous research (e.g., Black - Gutman \& Hickson, 1996; Kiesner et al. 2003, Poteat \& Anderson, 2012; Raabe \& Beelmann, 2011; Rutland, 1999; Van Zalk \& Kerr, 2014; White et al., 2009), we hypothesized threat and prejudice would be lower among Late adolescents and higher among early adolescents. Contrarily, the results suggested that between Early, and Late adolescents, Late adolescents perceived the highest amount of prejudice, realistic threat, and symbolic threat, and the lowest amount of negative stereotypes. Thus, we obtained partial support for $H 1$, which stated threat and prejudice will be lower among late adolescents and higher among early adolescents.

These results however contradict previous research and approaches that have examined the development of prejudice in adolescence, since previous research suggest prejudice should be higher among early adolescents and lower among Late adolescents or that prejudice should decrease with age in adolescence (Black - Gutman \& Hickson, 1996; Fishbein, 1996; Kiesner et al. 2003, Poteat \& Anderson, 2012; Raabe \& Beelmann, 2011; Rutland, 1999; Van Zalk \& Kerr, 2014; White et al., 2009). Nevertheless, several factors could explain why prejudice, realistic threat, and symbolic threat are higher among Late Finnish adolescents and why negative stereotyping is lower. Based on ITT, prejudice is higher among late adolescents because perceived threat (realistic and symbolic threats) with the exception of negative stereotyping is higher when compared to early and middle adolescents as earlier indicated. According to ITT, higher perception of threat should imply more feelings of prejudice (Riek, Mania \& Gaertner, 2006; Stephan et al., 1998; Stephan, Ybarra, \& Bachman, 1999) and this is the case with Late Finnish adolescents. Moreover, Late adolescence is a 
transitional stage to early adulthood (Hooghe \& Meeusen, 2012) and some late adolescents in Finland already experience some form of autonomy and are more likely to perceive economic difficulties in their lives, families or society. This transition makes them more susceptible to feelings of realistic threat. In addition, they may perceive greater realistic and symbolic threat because of a stronger identification with the ingroup (feelings of nationalism). According to the original theorization of ITT, ingroup identification is considered a predictor of perceived threat (Stephan, Renfro, \& Davis, 2008) and according to González et al. (2008):

The more people identify with their in-group, the more likely they are to be concerned about their group interests and to consider it important to preserve their own culture. Group identity functions as a group lens that makes people sensitive to anything that could harm their group. (p. 671)

For instance, in-group identification has been found to have a significant effect on realistic and symbolic threat (Riek, Mania, \& Gaertner, 2006). Individuals in the Netherlands who identified strongly with the Dutch ingroup were found to be more likely to perceive ethnic minorities as threatening to Dutch society and culture (Van Oudenhoven, Prins, \& Buunk, 1998). Even though in this study we did not include ingroup identification as a variable, research according to Way, Hernandez, Rogers, and Hughes (2013) shows ethnic or racial group belonging increases with age (e.g., Pahl \& Way, 2006; Quintana, 2007; Yip, Seaton, \& Sellers, 2006).

On the other hand, from RQ1, we found Finnish adolescents in general are not prone to negatively stereotype immigrants and it was also suggested that among the different groups, Late adolescents are the least likely to stereotype immigrants. In fact, the difference between early and middle adolescents was rather insignificant, while Late adolescents scored significantly lower than the other groups. This result suggest negative stereotyping remains relatively low and stable among early and middle adolescents but as they move to Late ado- 
lescence, negative stereotyping significantly drops or becomes even lower; supporting the idea that "As adolescents mature, they develop more complex cognitive skills and rely less on stereotypes" (Hooghe \& Meeusen, 2012, p 1.). One could also argue late adolescents have more opportunities to learn about immigrants either from school or through intergroup contact. This knowledge in turn counters stereotypical perceptions previously held about the outgroup. Literature on ITT suggest knowledge of the out-group and contact with the outgroup can affect the level of threat. Similarly, anxiety uncertainty management (AUM) theory, cultural theory and the white racial identity developmental model conclude that increased knowledge about an outgroup may lead to the reduction of stereotypes (Matusitz, 2012). This is related to the contact hypothesis of Allport (1954,) which stipulates intergroup contact will likely lesson stereotyping as it's a way of gaining knowledge about the "other" (Matusitz, 2012).

Another dimension in this study was to understand the correlation between Finnish adolescent's percieved threat and prejudice towards immigrants and to what extent the correlation differed between early and late adolescents. We proposed there would be a positive relationship between perceived threat and prejudice among Finnish adolescents" and sought to explore the extent to which the correlation between threat and prejudice would differ between Early, Middle and Late Finnish Adolescents. Our results clearly incated prejudice is positively correlated with realistic threat and symbolic threat but negatively corelated with negative stereotypes. Finnish adolescent's prejudice towards immigrants is related to the perception of realistic and symbolic threat and less likely with negative stereotyping. The finding that realistic threat and symbolic threat are positively related to prejudice is not new, as this result supports other studies and research on ITT that found a positive correlation between percieved threat and prejudice (Riek et al., 2006; Stephan \& Stephan, 1993, 1996; Stephan et al., 1998; Stephan et al., 1999). However, the negative 
correlation between prejudice and negative stereotyping is interesting and even more especially as the negative correlation between prejudice and negative stereotype remains stable between Early, Mid, and Late adolescents. These results are particularly surprising as research has also shown negative stereotyping to be positively associated with prejudice (Allport, 1954; Stephan et al., 1998, Stephan \& Stephan, 2000). This however indicates that negative stereotype is not important to the attitudes of Finnish adolescents (irrespective of their age ) towards immigrants. This may be due to exposure to other cultures and the development of more cognitive and complex skills espcially as they mature (Hooghe \& Meeusen, 2012). Moreover, the current public discourse about immigration in Finland especially amidst the influx of refugees into the country, is more centered around the economic and symbolic threat that they represent to the Finnish society rather than negative streotypes. There is also a possibility it might have something to do with the scale for negative stereotype. Even though we obtained a significant reliability, we are not sure if the sensitivity of the scale influenced the way they responded to this measure of negative stereotype. This represents a possibile limitation to this study.

However we recommend that future research should consider other factors that may mediate the relationship between threat and prejudice especially among Early, Middle and Late adolescents. So far this is the first study that attempts to understand the relationship between percieve threat and prejudice in the process of adolescence development (from early to late adolescence).

Therefore, this study contributes to research on prejudice by introducing an integrated threat approach to the study of prejudice from a developmental perspective particularly in adolescence which is considered to be a crucial and important stage in human development. Even though it is throughout these years that prejudice and attitude towards outgroups form and crystalize (Kiesner et al., 2003), until now, research had not considered 
percieved threats as a factor in the development of prejudice in adolescence. Moreover, this study contributes significantly to research on ITT by extending and showing its applicability in a developmental setting (adolescence). To the best of our knowledge, this is the first study in Finland and the world over that applies ITT in a sample of Early, Middle and Late adolescents in one study.

We recommend future research should consider a longitudinal approach in the application of ITT to better understand outgroup attitudes developmentally. Such a study is currently non existent. It would also be important to include other variables that could possibly explain the variance between the groups (Early, Middle and Late adolescent) in the way they percieve threat and how they feel towards immigrants. Moreover, it would be advantageous to evaluate how adolescents feel about specific immigrants, and not general "immigrants" as was done in the current study. It is possible that exploring perceptions of specific immigrant groups may provide insight into how adolescents perceive and conceptualize the world around them. In addition, just as Nshom and Croucher (2014) recommended in their study, we recommend exploring perceptions of threat from the majority viewpoint using qualitative methods. Most ITT studies are quantitative in nature. In depth interviews would help shed light on some extenuating factors related to threat and prejudice particularly in the process of adolescence.

Nevertheless, this study empirically shows us that among the different types of threats, realistic threat and symbolic threat are the most percieved from immigrants among Finnish adolescents. The study also revealed how these threats (realistic and symbolic threats) are also more prevalent among Late adolescents when compared to early and middle adolescents. Moreover, there was a positive relationship between prejudice and realistic threat and between prejudice and symbolic threat, but a negative relationship between prejudice and negative stereotyping and this relationship remains relatively stable from early 
to late adolescence. In conclusion, this study shows ITT to be an important factor in understanding the developement of prejudice in adolescence. 


\section{References}

Aberson, C. \& Gaffney, A. (2008) An integrated threat model of explicit and implicit attitudes. European Journal of Social Psychology, 39, 808-830.

Abrams, D., \& Rutland, A. (2008). The development of subjective group dynamics. In S. R. Levy \& M. Killen (Eds.), Intergroup attitudes and relations in childhood through adulthood (pp. 47-65). New York, NY: Oxford University Press.

Aboud, F. E. (1988). Children and prejudice. Oxford, UK: Blackwell.

Allport, G. (1954). The nature of prejudice. Cambridge MA: Addison-Wesley.

Bergen Jr., T. J. (2001). The development of prejudice in children. Education, 122(1), 154.

Bigler, R. S. \& Liben, L. S. (1993). A cognitive-developmental approach to racial stereotyping and reconstructive memory in Euro-American children. Child Development, $64,1507-1518$

Bizman, A. \& Yinon, Y. (2010). Intergroup and interpersonal threats as determinants of prejudice: The moderating role of in-group identification. Basic and Applied Social Psychology, 23, 191-196.

Buss, A. H. (1961). The psychology of aggression. New York, NY: Wiley.

Curseu, P. L., Stoop, R., \& Schalk, R. (2007). Prejudice toward immigrant workers among Dutch employees: Integrated theory revisited. European Journal of Pyschology, 37, $125-140$

Croucher, S. M., Aalto, J., Hirvonen, S., \& Sommier, M. (2013). Integrated threat and intergroup contact: An analysis of Muslim immigration to Finland. Human Communication, 16, 109 - 120.

Croucher, S. M. (2013). Integrated threat theory and acceptance of immigrant assimilation: An analysis of Muslim immigration in Western Europe. Communication Monographs, 80, 46 - 62 . 
Croucher, S. M., Homsey, D., Brush, E., Buyce, C., DeSilva, S., \& Thompson, A. (2013).

Prejudice toward American Muslims: An integrated threat analysis. Journal of Intercultural Communication, 32, http://immi.se/intercultural/.

Croucher, S. M., Galy-Badenas, \& Routsalainen, M. (2014). Host culture acceptance, religiosity, and the threat of Muslim immigration: An integrated threat analysis in Spain. Journal of Intercultural Communication, 35.http://www.immi.se/intercultural/

Carter, C. \& Rice, C. (1997). Acquisition and manifestation of prejudice in children. Journal of Multicultural Counseling \& Development, 25, 185-194.

Doyle, A. B. \& Aboud, F. (1995). A longitudinal study of white children's racial prejudice as a Social-cognitive development. Merrill-Palmer Quarterly, 41, 209-228.

Egharevba Stephen (2011). Understanding the racial nature of police and immigrant relations in Finland: The case of Africans in Turku. Department of social policy University of Turku. accessed 29/09/2015. https://www.doria.fi/bitstream/handle/10024/70725/AnnalesB331.pdf? sequence=1.

Ervasti, H. (2004). Attitudes towards foreign-born settlers: Finland in a comparative perspective. Teoksessa I. S. (Ed.), Yearbook of population research in Finland (pp. 25-44). Helsinki, Finland: Väestöliitto, Väestöntutkimuslaitos.

Fischer, K. W., \& Lamborn, S. (1989). Mechanisms of variation in developmental levels: Cognitive and emotional transition during adolescence. In A. de Ribaupierre (Ed.), Transition mechanisms in child development: The longitudinal perspective (pp. 3367). Cambridge, UK: Cambridge University Press.

González, K. V., Verkuyten, M., Weesie, J., \& Poppe, E. (2008). Prejudice towards Muslims in The Netherlands: Testing integrated threat theory. British Journal of Social Pyschology, 47, 667-685. 
Harrison, N. \& Peacock, N. (2010) Cultural distance, mindfulness and passive xenophobia: using Integrated Threat Theory to explore home higher education students' perspectives on 'internationalisation at home'. British Educational Research Journal, 36, 877-902.

Hooghe M. \& Meeusen, C. (2012). Homophobia and the transition to adulthood: A three year panel study among Belgian late adolescents and young adults. Journal of Youth and Adolescence, 41, 1197-1207.

Hoover R. \& Fishbein, H. (1999). The development of prejudice and sex role stereotyping in white adolescents and white young adults. Journal of Applied Developmental Psychology, 20, 431-448.

Islam, R. M. \& Hewstone, M. (1993). Dimensions of contact as predictors of intergroup anxiety, perceived outgroup variability, and out-group attitude: An integrative model. Personality and Social Psychology Bulletin, 19, 700-710.

Jaakkola, M. (2000). Finnish Attitudes towards immigrants in 1987-1999. (I. Söderling, Toim.) Helsinki, Finland: Väestöntutkimuslaitos.

Jaakkola, M. (2009). Maahanmuuttajat suomalaisten näkökulmasta. Asennemuutokset 19872007. Helsinki, Finland: City of Helsinki Urban Facts Research Series.

Jasinskaja-Lahti, I. \& Liebkind, K. (2001). Perceived discriminaion and psychological adjustment among Russian-speaking immigrant adolescents in Finland. International Journal of Psychology, 36, 174-185.

Katz, P. A., \& Ksansnak, K. R. (1994). Developmental aspects of gender role flexibility and traditionality in middle childhood and adolescence. Developmental Psychology, 30, $272-282$.

Kiesner, J., Maass, A., Cadinu, M., \& Vallesse, I. (2003). Risk factors for ethnic prejudice during early adolescence. Social Development, 12, 288-308. 
Killen, M., Margie, N. G., \& Sinno, S. (2006). Morality in the context of intergroup relationships. In M. Killen \& J. G. Smetana (Eds.), Handbook of moral development (pp. 155-183). Mahwah, NJ: Erlbaum.

Kohlberg, L., \& Candee, D. (1984). The relationship of moral judgment to moral action. In W. M. Kurtines \& J. L. Gewirtz (Eds.), Morality, moral behavior, and moral development (pp. 52-73). New York: Wiley.

Kyntäjä, E. (1997). Ethnic remigration from the former Soviet Union to Finland-patterns of ethnic identity and acculturation among the Ingrian Finns. Teoksessa S. S. (Ed.), Yearbook of Population Research in Finland (pp. 102-113). Helsinki, Finland: Väestöliitto, Väestöntutkimuslaitos

Ljujic, V., Vedder, P., Dekker, H., \& Geel, M. (2013). Romaphobia among Serbian and Dutch adolescents: The role of perceived threat, nationalistic feelings, and integrative orientations. International Journal of Psychology, 48, 352-362.

Ljujic, V., Vedder, P., \& Dekker, H. (2012). Romaphobia among Serbian adolescents: The role of national in-group attitudes and perceived threat. Political Psychology, 33, 911-924.

Matusitz, J.(2012), Relationship between knowledge, stereotyping and prejudice in Interethnic communication, Journal of Tourism and Cultural Heritage, 10, 89-98.

Meertens, R. W. \& Pettigrew, T. F. (1997). Is subtle prejudice really prejudice? Public Opinion Quarterly, 61, 54-71

Nesdale, D. (1999). Ethnic prejudice in children: A social identity model. In P. R. Martin \& W. Noble (Eds.), Psychology and Society (pp. 92-110). Brisbane, Australia: Australian Academic Press. 
Nshom, E. \& Croucher, S. M. (2014). Threats and attitudes toward Russian-speaking immigrants: a comparative study between younger and older Finns. Russian Journal of Communication, 6, 308-317.

Oskamp. S. (1991). Attitudes and Opinions. Englewood Cliffs, NJ: Prentice Hall.

Oskamp, S. (2000). Reducing prejudice and discrimination. Mahwah, NJ: Lawrence Erlbaum Associates, Inc.

Pahl, K., \& Way, N. (2006). Longitudinal trajectories of ethnic identity among urban Black and Latino adolescents. Child Development, 77, 1403-1415.

Pettigrew, T. F. \& Meertens, R. W. (1995). Subtle and blatant prejudice in Western Europe. European Journal of Social Psychology, 25, 57-75.

Pitkänen, P., \& Kouki, S. (2002). Meeting foreign cultures: a survey of the attitudes of Finnish authorities towards immigrants and immigration. Journal of Ethnic and Migration Studies, 28(1), 103-118.

Poteat, V. P., \& Anderson, C. J. (2012). Developmental changes in sexual prejudice from early to late adolescence: The effects of gender, race, and ideology on different patterns of change. Developmental Psychology, 48, 1403-1415.

Quintana, S. M. (2007). Racial and ethnic identity: Developmental perspectives and research. Journal of Counseling Psychology, 54, 259-270.

Raabe, T. \& Beelmann, A. (2011). Development of ethnic, racial, and national prejudice in childhood and adolescence: A multinational meta-analysis of age differences. Child Development, 82, 1715-1737.

Riek, B. M., Mania, E. W., \& Gaertner, S. L. (2006). Intergroup threat and the integrated threat theory: A meta-analytic review. Personality and Social Psychology Review, $10,336-353$. 
Rus, A. \& Madrid, D. (1998). An overview of prejudice: Some Spanish studies, International Journal of Political Psychology and Political Socialization, 7, 117-130.

Schneider, S. L. (2008). Anti-immigrant attitudes in Europe: Outgroup size and perceived ethnic threat. European Sociological Review, 24, 53-67.

Scheibner, G. \& Morrison, T. (2009). Attitudes towards Polish immigrants to the Republic of Ireland: An integrated threat analysis. Ethnic and Racial Studies, 32, 1431-1448.

Spencer-Oatey, H. (Ed.). (2008). Culturally speaking: Culture, communication and politeness theory (2nd ed.). London: Bloomsbury Publishing.

Stephan, W. G. \& Stephan, C. W. (1993). Cognition and affect in stereotyping: Parallel interactive networks. In D. M. Mackie \& D. L. Hamilton (Eds.), Affect, cognition and stereotyping: Interactive processes in group perception (pp. 111-136). Orlando, FL: Academic Press.

Stephan W. G. \& Stephan C. W. (2000). An integrated threat theory of prejudice in S. Oskamp (Ed.), Reducing Prejudice and discrimination (pp. 225-246). Hillsdale, NJ, Lawrence Erlbaum.

Stephan, W. G., Boniecki, K. A., Ybarra, O., Bettencourt, A., Ervin, K. S., Jackson, L. A., McNatt S. P. Renfro L. C. (2002). The role of threats in the racial attitudes of Blacks and Whites. Personality and Social Psychology Bulletin, 28, 1242-1254.

Stephan W. G. \& Stephan, C. W. (1996). Predicting prejudice. International Journal of Intercultural Relations, 20, 409-426.

Stephan, W. G., Diaz-Looving, R., \& Duran, A. (2000). Integrated threat theory and intercultural attitudes: Mexico and the United States. Journal of Cross-Cultural Psychology, 31, 240-249.

Stephan, W. G., Renfro, C. L. \& Davis, M. D. (2008). The role of threat in intergroup relations. In U. Wagner, L. R. Tropp, G. Finchilescu, \& C. Tredoux (Eds.), 
Improving intergroup relations: Building on the legacy of Thomas F.Pettigrew (pp. 55-72). Oxford, UK: Blackwell Publishing Ltd..

Stephan, W. G., Ybarra, O., \& Bachman, G. (1999). Prejudice toward immigrants: An integrated threat theory. Journal of Applied Social Psychology, 29, 2221-2237.

Stephan, W. G., Ybarra, O., Martinez, C., Schwarzwald, J., \& Turk-Kaspa, M. (1998). Prejudice toward immigrants to Spain and Israel: An integrated threat theory analysis. Journal of Cross Cultural Psychology, 29, 559-576.

Statistics Finland (2014) Demographic statistics: http://www.stat.fi/tup/suoluk/suoluk_vaesto_en.html\#\#foreigners

Tarvas, T. \& Martikainen, T. (2012). Islampelko on pysynyt aisoissa. Europa. Retrieved from: http://www.europalehti.fi/2012/08/islampelko-on-pysynyt-aisoissa/

Tajfel, H. \& Turner, J. C. (1979). An integrative theory of intergroup conflict. In G. Austin \& S. Worchel (Eds.), The social psychology of intergroup relations (pp. 33-47). Monterey, CA: Brooks/Cole.

Van Oudenhoven, J. P., Prins, K. S., \& Buunk, B. P. (1998). Attitudes of minority and majority members towards adaptation of immigrants. European Journal of Social Psychology, 28, 995-1013.

Van Zalk, M. H. W., \& Kerr, M. (2014). Developmental trajectories of prejudice and tolerance toward immigrants from early to late adolescence. Journal of Youth and Adolescence, 43, 1658-1671.

Valsiner, J., \& Connolly, K. J. (Eds.). (2003). Handbook of developmental psychology. London, UK: Sage.

Way, N., Hernández, M. G., Rogers, L. O., \& Hughes, D. L. (2013). “I'm not going to become no rapper": Stereotypes as a context of ethnic and racial identity development. Journal of Adolescent Research 28, 407-430. 
White, F. A., Wootton, B., Man, J., Diaz, H., Rasiah, J., Swift, E., \& Wilkinson, A. (2009). Adolescent racial prejudice development: The role of friendship quality and interracial contact. International Journal of Intercultural Relations, 33, 524-534.

Webster, R. J., Saucier, D. A., \& Harris, R. J. (2010). Before the measurement of prejudice: Early psychological and sociological papers on prejudice. Journal of the History of Behavioral Sciences, 46, 300-313.

White, F. A. \& Gleitzman, M. (2006). An examination of family socialization processes as moderators of racial prejudice transmission between adolescents and their parents. Journal of Family Studies, 12, 247-260.

Yip, T., Seaton, E. K., \& Sellers, R. M. (2006). African American racial identity across the lifespan: Identity status, identity content, and depressive symptoms. Child Development, 77, 1504-151.

Yle (2015). Anti-Immigration protest draws 200 in Helsinki. Accessed 29/09/2015. http://yle.fi/uutiset/anti-immigration protest draws 200 in helsinki/8317805 
Table 1

Means, Standard Deviations, Correlations, and Alpha Reliabilities for Study Variables

Full Sample

$\begin{array}{lllllll}\text { Variable } & M & S D & \alpha & \text { (1) } & \text { (2) } & \text { (3) }\end{array}$

$\begin{array}{llllllll}\text { (1) Realistic Threat } & 3.60 & 1.23 & .89 & - & & \\ \text { (2) Symbolic Threat } & 3.74 & 1.32 & .85 & .82^{* *} & - & \\ \text { (3) Stereotypes } & 2.12 & .73 & .85 & -.22^{* *} & -.23^{* *} & - \\ \text { (4) Prejudice } & 3.85 & .69 & .71 & .21^{* *} & .25^{* *} & -.64^{* *} & -\end{array}$

$\underline{\text { Early Adolescents }}$

Variable $M \quad S D$

(1) (2)

(3)

(4)

(1) Realistic Threat $\quad 3.48 \quad 1.35$

(2) Symbolic Threat $\quad 3.58 \quad 1.51$

$.88^{* *}-$

(3) Stereotypes

$2.20 \quad .82$

$-.10-.07 \quad-$

(4) Prejudice

$3.79 \quad .70$

$.14 * \quad .16^{*}-.66^{* *}-$

$\underline{\text { Mid Adolescents }}$

Variable $M \quad S D$

(1) (2)

(1) Realistic Threat $\quad 3.47 \quad 1.25$

(2) Symbolic Threat

$3.62 \quad 1.34$

$.81 * * \quad-$

(3) Stereotypes

$2.21 \quad .78$

$-.24 * * \quad-.25 * * \quad-$

(4) Prejudice

$3.81 \quad .75$

$.17 * * \quad .24 * * \quad-.66^{* *} \quad-$

$\underline{\text { Late Adolescents }}$

$\underline{\text { Variable }}$ $M \quad S D$

(1) (2)

(3)

(4)

(1) Realistic Threat

$3.82 \quad 1.12$

(2) Symbolic Threat

4.00

1.14

$.78 * *-$

(3) Stereotypes

$1.96 \quad .56$

$.-24 * * \quad-.28 * * \quad-$

(4) Prejudice

3.94

$.28 * * \quad .32 * * \quad-.57 * *-$ 
Note: $* * p<.01, * * * p<.001$. 


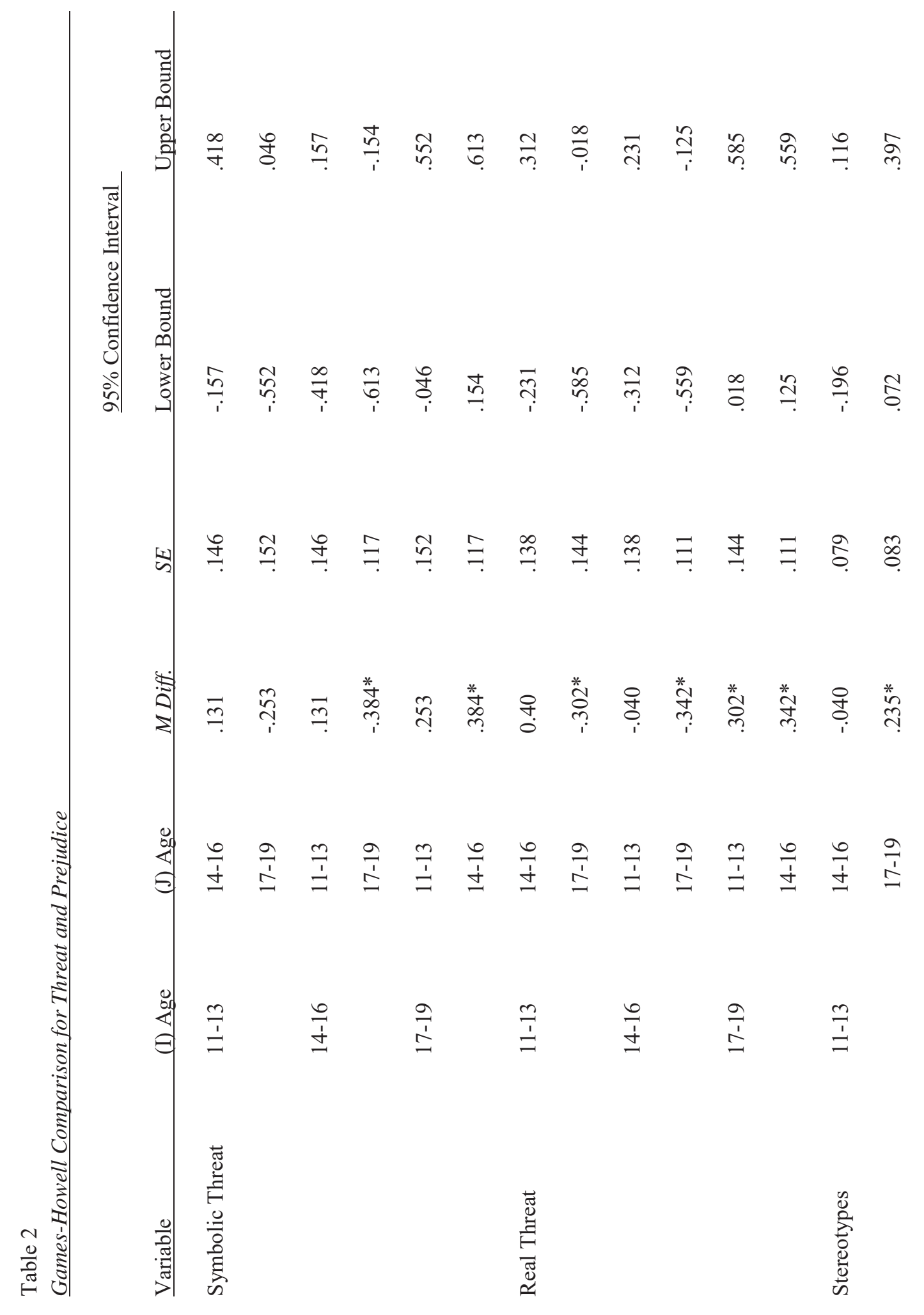




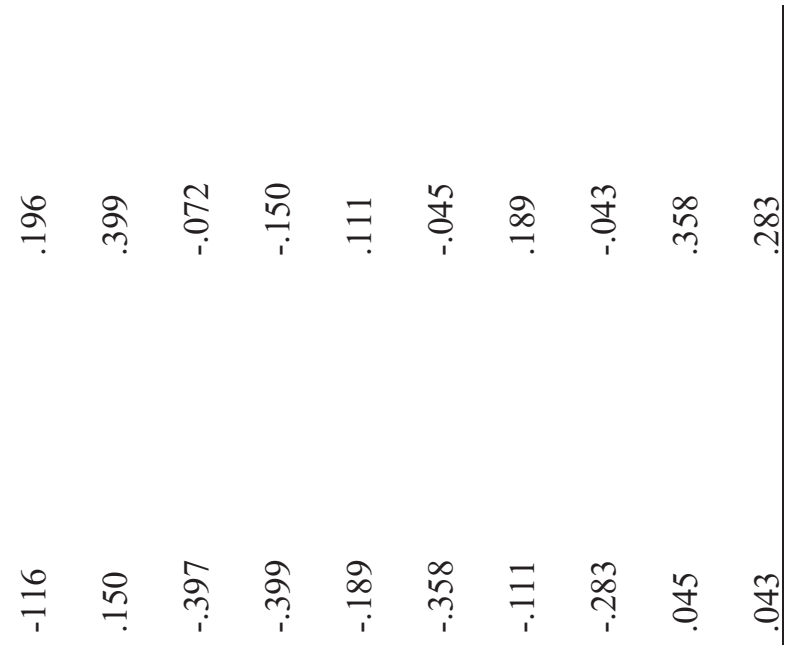

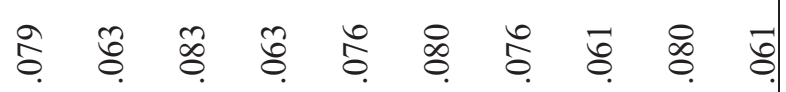

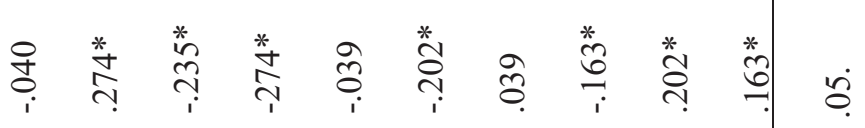

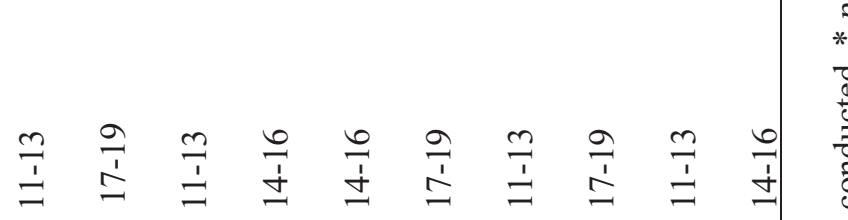

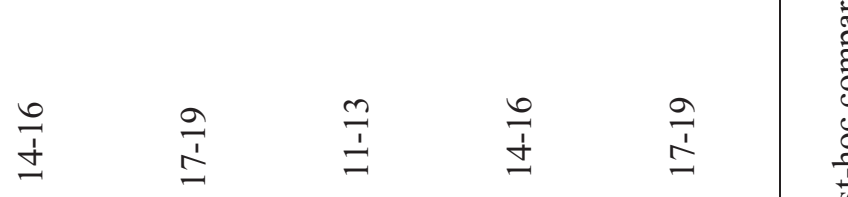

$$
\begin{aligned}
& \text { लี } \\
& \text { 造 }
\end{aligned}
$$

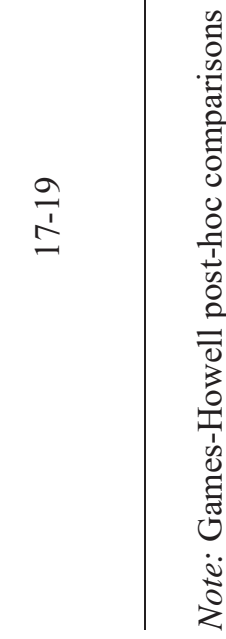


Table 3

Fisher's z-Comparison Results

$\underline{\text { Realistic Threat X Prejudice }}$

Early Adolescents $r$ Mid Adolescents $r$ Fisher's Z

.14

.17

1.44 (ns)

Early Adolescents $r$ Late Adolescents $r$

Fisher's Z

.14

.28

$1.46(n s)$

Mid Adolescents $r$

Late Adolescents $r$

Fisher's Z

.17

.28

$.32(n s)$

$\underline{\text { Symbolic Threat X Prejudice }}$

Early Adolescents $r$ Mid Adolescents $r$ Fisher's Z

.16 .24 .87 (ns)

Early Adolescents $r$ Late Adolescents $r$ Fisher's Z

.16 .32 1.59 (ns)

Mid Adolescents $r$ Late Adolescents $r$ Fisher's Z .24 .32 .97 (ns)

$\underline{\text { Stereotypes X Prejudice }}$

Early Adolescents $r$ Mid Adolescents $r$ Fisher's Z

$-.66$

$-.66$ 0 (ns)

Early Adolescents $r$ Late Adolescents $r$ Fisher's Z $-.66$ $-.57$ 1.81 (ns)

Mid Adolescents $r$ Late Adolescents $r$ Fisher's Z $-.66$ $-.57$ 1.81 (ns) 